\title{
Renal Bicarbonate Reabsorption and Hydrogen Ion Excretion in Normal Infants*
}

\author{
Chester M. Edelmann, Jr., $\dagger$ Juan Rodriguez Soriano, Hayim Boichis, \\ Alan B. Gruskin, and Melinda I. Acosta \\ (From the Department of Pediatrics, Albert Einstein College of Medicine-Bronx Municipal \\ Hospital Center, Bronx, N. Y.)
}

\begin{abstract}
Summary. After acute administration of ammonium chloride, infants 1 to 16 months of age were similar to older children in their capacity to acidify their urine. The infants had a higher rate of excretion of titratable acid and a lower rate of excretion of ammonium but were similar in their rate of excretion of total hydrogen ion.

Bicarbonate titrations performed in infants during the first year of life demonstrated a threshold ranging from 21.5 to 22.5 mmoles per $\mathrm{L}$, maximal rate of reabsorption from 2.6 to 2.9 mmoles per $100 \mathrm{ml}$ glomerular filtrate, and marked titration splay. A nephronic frequency distribution curve of the ratio of glomerular filtration rate to tubular reabsorptive capacity demonstrated both heterogeneity and skewing to the right, suggesting the presence of significant numbers of nephrons with low tubular transport capacity relative to filtration rate.

It is suggested that the "physiologic acidosis" of the infant is due neither to a limited renal capacity to excrete hydrogen ion nor to a reduced capacity for reabsorption of bicarbonate, but rather to a low renal plasma bicarbonate threshold. Although the level of the threshold may relate to the kinetics of bicarbonate reabsorption during this period, it appears to be due at least in part to functional and morphologic heterogeneity of nephrons.
\end{abstract}

\section{Introduction}

It is well established that the concentration of bicarbonate in the plasma of normal infants is lower than that observed later in childhood and adult life $(1,2)$. Although this "physiologic acidosis" is usually attributed to a limited capacity of the kidney to excrete the acid load imposed by diet (2), inadequate data during this period are avail-

* Submitted for publication November 28, 1966; accepted May 5, 1967.

Supported in part by U. S. Public Health Service research grants 5 TI HE 5267 and HE 05561 from the National Heart Institute, The Kidney Foundation of New York, and the Sylvan League, Inc.

$\dagger$ Recipient of a Research Career Development Award from the National Institute of Child Health and Human Development (1-K3-HD 19369).

Address requests for reprints to Dr. Chester M. Edelmann, Jr., Albert Einstein College of Medicine, 1300 Morris Park Ave., Bronx, N. Y. 10461. able to permit acceptance or rejection of this hypothesis. In subjects in hydrogen ion balance, the concentration of bicarbonate in blood is maintained at a level just below the so-called renal plasma bicarbonate threshold (3). The present investigations were designed 1 ) to investigate the relationship between renal reabsorption and excretion of bicarbonate and the concentration of bicarbonate in blood of infants during the first year of life, and 2) to compare infants and older children in their responses to administration of ammonium chloride.

\section{Methods}

Studies of bicarbonate reabsorption were performed in six infants aged 1 to 12 months (Table II). The response to ammonium chloride was studied in 11 infants aged 1 (3), 2, 3, 4, 5, 6 (2), 8, and 16 months and 10 children aged 7 to 12 years. The older children were hospitalized for minor illnesses or for elective surgery. The latter were studied either before or at least 5 days 


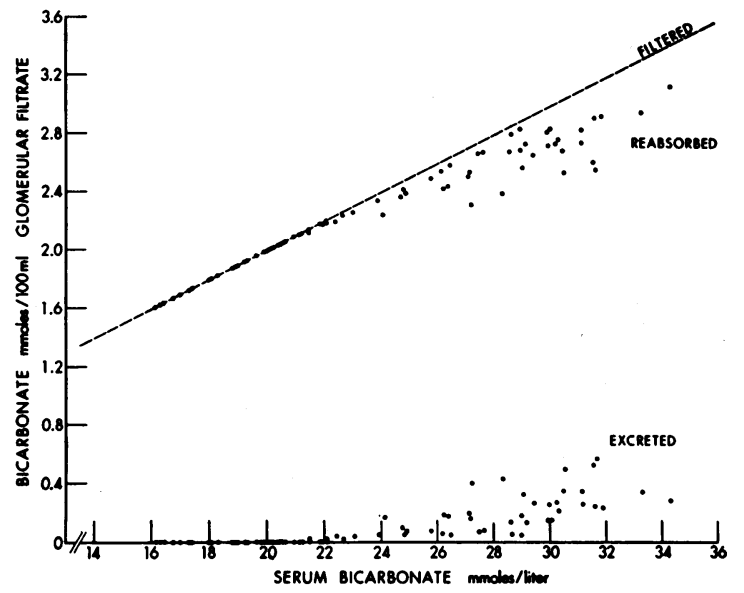

Fig. 1. Rates of filtration, REABsorption, AND URINARY EXCRETION OF BICARBONATE DURING BICARBONATE INFUSION.

after surgery, and no subject undergoing major surgery was included. Subjects with any type of renal disease or nonrenal disorder that might affect water and electrolyte or acid-base metabolism were excluded. All subjects fell within the tenth and seventy-fifth percentiles for height and weight.

The investigations were performed with institutional approval. Informed parental consent was obtained before study.

Bicarbonate reabsorption. Investigation of bicarbonate reabsorption was performed by the continuous infusion of a solution containing sodium bicarbonate, inulin, and $p$-aminohippurate (PAH). Bicarbonatae, withheld from the initial infusion to permit control collections, was infused at a rate calculated to produce an increase in serum bicarbonate of 2 mmoles per $\mathrm{L}$ per hour; when the bicarbonate threshold was reached, as judged by increase in urinary $\mathrm{pH}$ to between 6.5 and 7.0 , the rate of infusion of bicarbonate was increased by a factor of 1.5 to 2.0 and maintained until serum bicarbonate concentration exceeded 30 mmoles per $\mathrm{L}$ for several periods.

Urine collections were made at half-hour intervals, utilizing an indwelling urethral catheter. Urine was collected under mineral oil, and completeness of the collection was assured by manual suprapubic pressure. The initial urine obtained during each study was utilized for urinalysis and culture. Bacteriuria was never demonstrated in these urines or in clean-voided specimens collected serially after catheterization.

Blood samples were obtained anaerobically at the midpoint of each urine collection from an indwelling needle placed in a superficial vein of the arm or hand. Use of a tourniquet was avoided. Blood samples were centrifuged and analyzed anaerobically for $\mathrm{pH}$ and $\mathrm{CO}_{2}$ content.

Response to $\mathrm{NH}_{4} \mathrm{Cl}$. Studies were performed in the renal unit and were begun uniformly between 8 and 9 a.m. The patients remained recumbent during the test, but were allowed free movement in bed. Breakfast was permitted on the day of the test, and a usual lunch was given at the appropriate time. In order to ensure an adequate and fairly constant rate of urine flow, we administered water throughout the test at the rate of $50 \mathrm{ml}$ per hour per $\mathrm{m}^{2}$. In the older subjects urines were collected at hourly intervals by spontaneous voiding. Urine specimens in infants were obtained through indwelling urethral catheters, complete emptying being assured by air washout. Urine specimens were not collected under oil but were examined immediately for $\mathrm{pH}$ and titratable acid and were stored for other determinations in airfree containers.

Arterialized capillary blood samples were collected in heparinized tubes for determination of $\mathrm{pH}, \mathrm{CO}_{2}$ tension, $\left(\mathrm{PCO}_{2}\right)$, and total $\mathrm{CO}_{2}$ content. Blood specimens for other determinations were obtained from superficial veins during free flow.

After collection of two 30 - to 60 -minute control urine samples, control samples of venous and capillary blood were obtained. Ammonium chloride was given by mouth over the course of the next hour; it was taken in gelatin capsules or in water flavored with lemon juice and sugar by the older children and administered by stomach tube as a 5 to $10 \%$ solution in the infants.

After administration of the ammonium chloride, five test urine samples, each taken over approximately $60 \mathrm{~min}$ utes, were collected. Further blood samples were obtained 3 to 4 hours after the ingestion of ammonium chloride was completed. The dosage of ammonium chloride in infants was $75 \mathrm{mEq}$ per square meter body surface area (equivalent to $3.9 \mathrm{mEq}$ per $\mathrm{kg}$ body weight). Children received $150 \mathrm{mEq}$ per square meter $(5.4 \mathrm{mEq}$ per $\mathrm{kg}$ ).

Blood and urine $\mathrm{pH}$ were measured at $38^{\circ} \mathrm{C}$ with a Radiometer $\mathrm{pH}$ meter and microelectrode chain. Carbon dioxide content $\left(\mathrm{tCO}_{2}\right)$ was determined by the method of Van Slyke and Neill (4), using a Natelson microgasometer. The $\mathrm{PCO}_{2}$ and bicarbonate concentration were calculated from the Henderson-Hasselbach equation. For serum, values employed for $\mathrm{pK}^{1}$ and $\alpha$ were 6.10 and 0.0301 , respectively. The values for $\mathrm{pK}^{1}$ were calculated for each urine sample according to the formula $6.33-0.5 \mathrm{VB}$, where $B$ represents the total cation concentration estimated as the sum of $\mathrm{Na}+\mathrm{K}$, expressed in equivalents per liter (5). Curves of bicarbonate reabsorption and excretion were constructed and plotted according to the method of Pitts, Ayer, and Schiess (6). Corrections were not made for either Donnan equilibrium or transit time between glomerulus and urinary bladder.

Urinary titratable acid was measured by immediate titration at $25^{\circ}$ to $\mathrm{pH} 7.7$, using a Coleman Metrion II $\mathrm{pH}$ meter. The end point of 7.7 instead of 7.4 was chosen to correct for temperature. Urinary ammonium was measured by the microdiffusion method of Conway (7). Sodium and potassium were measured utilizing a Perkin-Elmer flame photometer, model 146. Chloride was determined coulometrically using the method of Cotlove, Trantham, and Bowman (8). Creatinine and phosphorus were determined on the Technicon 


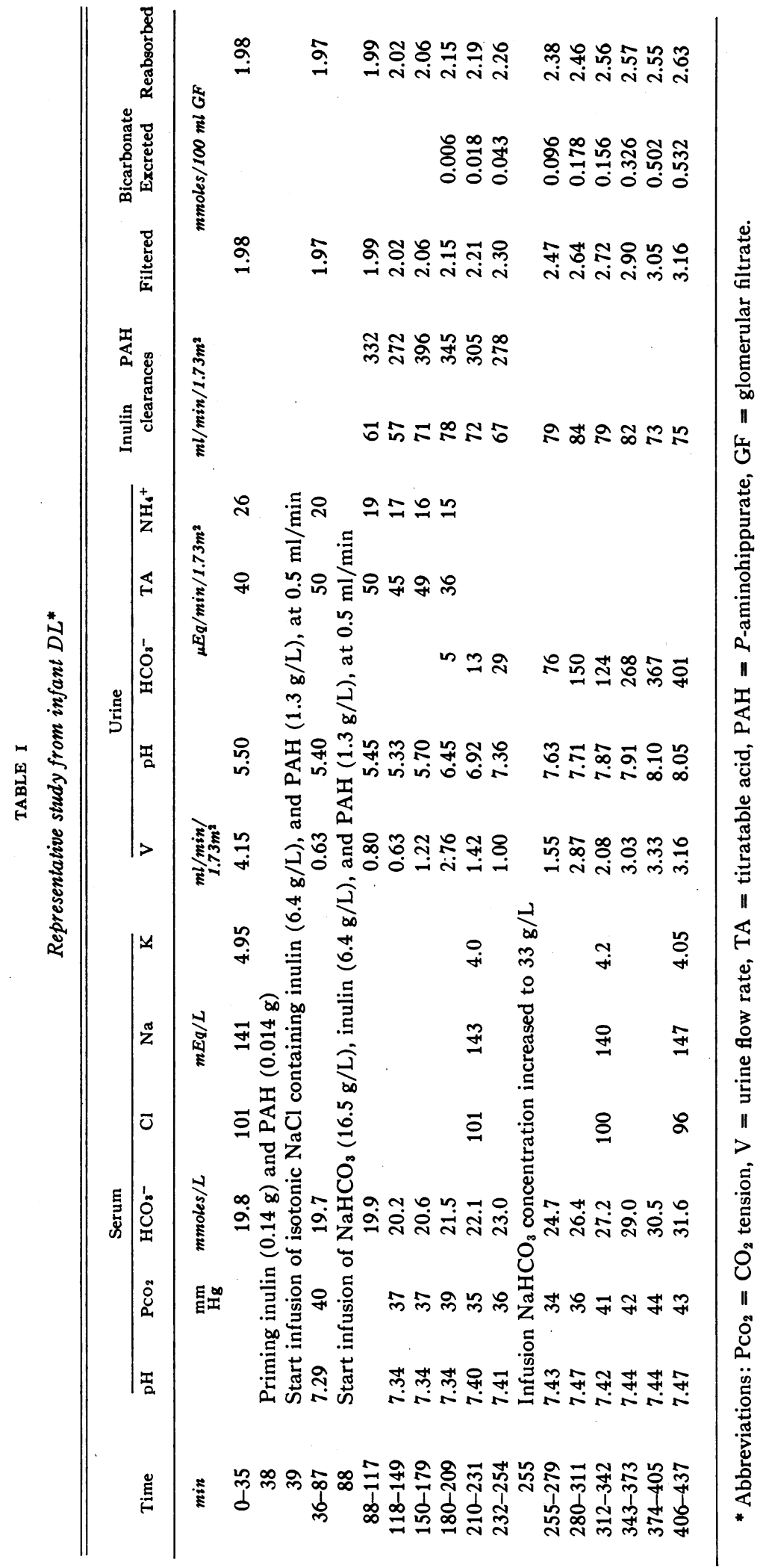




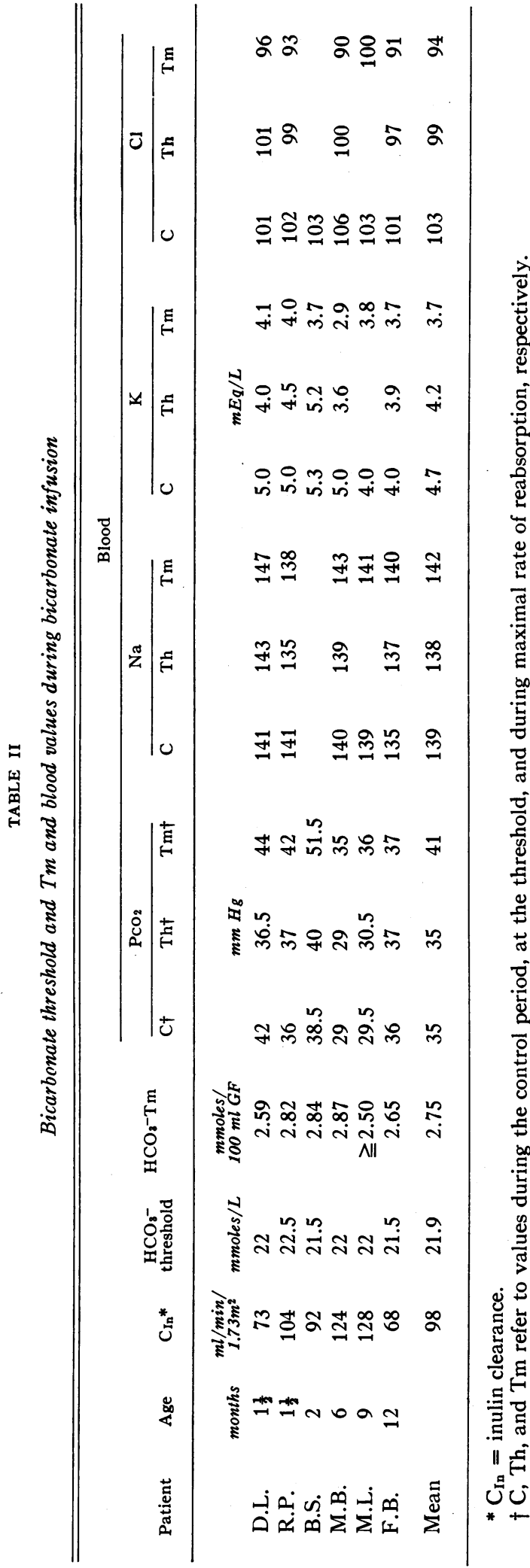

Autoanalyzer, using modifications of standard methods. Inulin was determined by a modification of the method of Schreiner (9). p-Aminohippurate was measured by a modification of the method of Smith and co-workers (10). Statistical comparisons were performed by means of Student's $t$ test according to Snedecor (11).

\section{Results}

Bicarbonate reabsorption. Data from a representative study are given in Table $I$. The data from all studies are plotted in Figure 1, in which rates of reabsorption and excretion of bicarbonate, expressed as millimoles per $100 \mathrm{ml}$ glomerular fil-

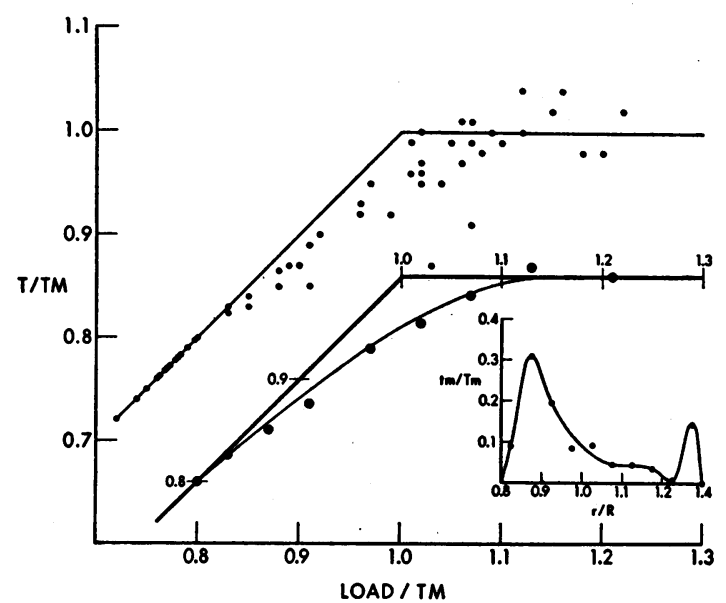

Fig. 2. MASS PLOT, MEAN CURVE, AND FREQUeNCY disTRIBUTION CURVE FOR THE DATA SHOWN IN FIGURE 1. The terms $\mathrm{T} / \mathrm{Tm}$ and load/Tm refer to individual rates of bicarbonate reabsorption and filtration, respectively, divided by the corresponding maximal rate of transport. This treatment allows data from all infants to be included in the same plot. A mass plot of data from all observations is presented in the upper graph. Mean curve of the data, shown in the lower graph, was derived by averaging the data in blocks of $\Delta$ load/Tm $=$ 0.05 , the smooth curve being drawn by inspection. The frequency distribution curve, shown in the insert, was drawn according to the method of Smith (12). The rate of bicarbonate reabsorption in saturated nephrons, expressed as a fraction of the maximal rate of reabsorption for both kidneys, is given by the ratio $\mathrm{tm} / \mathrm{Tm}$. This ratio, therefore, serves as an index of the fraction of the total nephron population. $r / R$ is the ratio of glomerulotubular balance of groups of nephrons ( $r$, calculated as the ratio of their glomerular filtration rate to their maximal rate of bicarbonate reabsorption) to the mean value for glomerulotubular balance of the total nephron population (R). The frequency distribution curve, therefore, represents the per cent of the total nephron population with particular levels of glomerulotubular balance, related to the mean value for the two kidneys. 


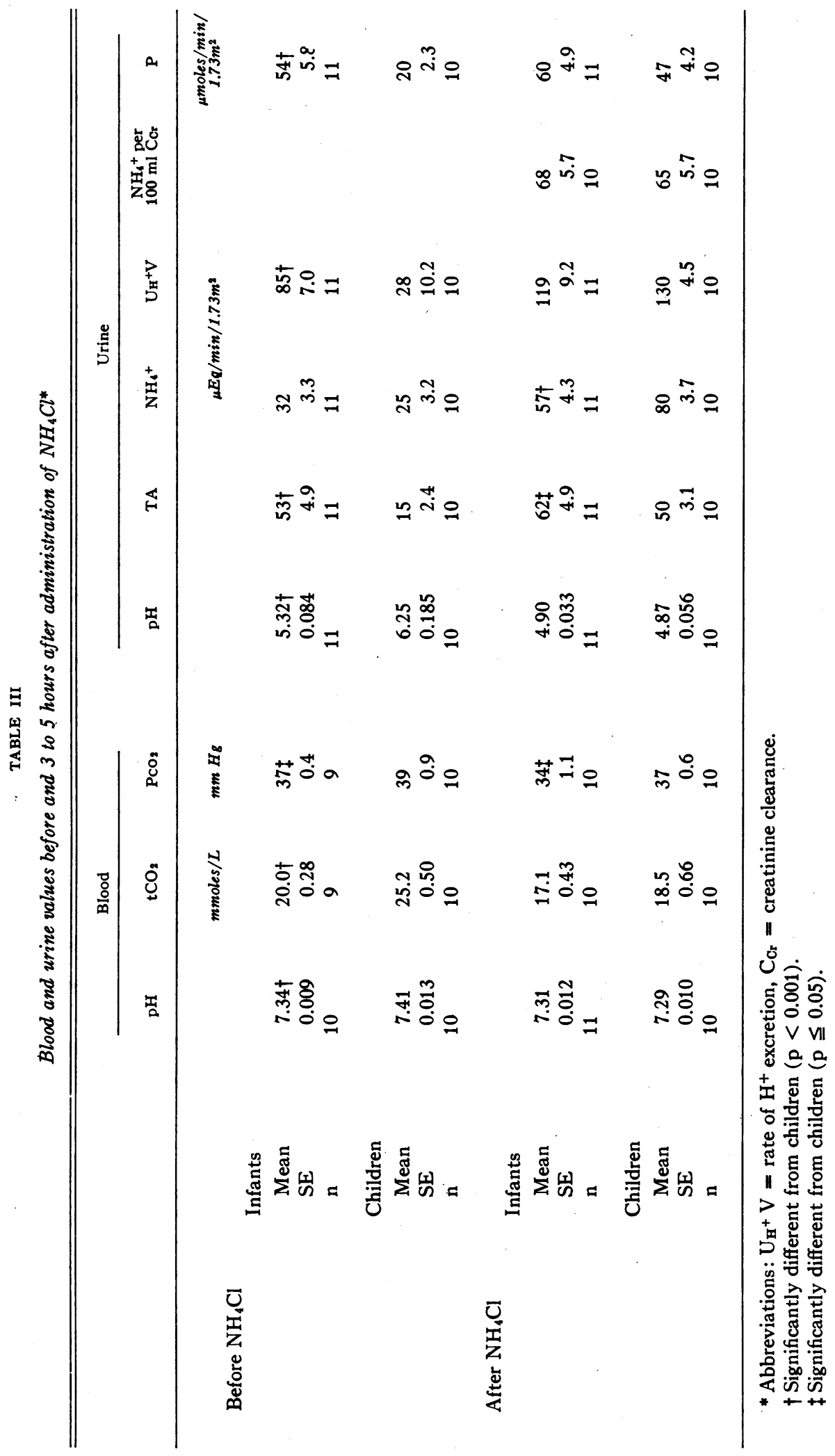


trate $(\mathrm{GF})$, are plotted against serum bicarbonate concentration in millimoles per liter. The diagonal line in the figure represents the rate of filtration of bicarbonate in millimoles per $100 \mathrm{ml} \mathrm{GF}$. As shown in the Figure, urinary excretion of bicarbonate remained essentially zero until serum concentrations exceeded 22 mmoles per L; thereafter, bicarbonate appeared in the urine in significant amounts (more than 0.01 to 0.02 mmoles per $100 \mathrm{ml} \mathrm{GF}$, and increasing rapidly), defining the renal plasma threshold. The maximal rate of tubular reabsorption of bicarbonate $(\mathrm{Tm})$ ranged from 2.6 to 2.9 mmoles per $100 \mathrm{ml} \mathrm{GF}$. In individual studies (with the exception of ML), rates of reabsorption were constant during the last two or three periods, despite increasing concentrations of bicarbonate in blood. Nevertheless, it is possible that greater rates of reabsorption of bicarbonate might have been observed had blood bicarbonate concentration been raised to higher levels. The term $\mathrm{Tm}$ is used, therefore, to indicate the maximal rate observed; if actual values of $\mathrm{Tm}$ in infants are greater, interpretation of the data would not be changed.

Individual and mean values for bicarbonate threshold and $\mathrm{Tm}, \mathrm{PCO}_{2}$, and concentrations of sodium, potassium, and chloride in serum during the test are given in Table II.

In Figure 2 the ratio of reabsorbed bicarbonate to $\mathrm{Tm}$ is plotted as a function of the ratio of filtered bicarbonate to $\mathrm{Tm}$. Both individual points from each infant as well as the mean response of the group are shown. If all nephrons functioned identically and if filtered bicarbonate were totally reabsorbed until the $\mathrm{Tm}$ was reached, points would fall along the theoretical curve. However, a marked deviation from the theoretical line or "titration splay" is apparent.

Response to ammonium chloride. Measurements obtained in infants and children in blood and urine samples obtained before and 3 to 5 hours after administration of ammonium chloride are shown in Table III.

During the control period the mean $\mathrm{pH}$ and $\mathrm{tCO}_{2}$ in the infants of 7.34 and 20.0, respectively, demonstrate the physiologic acidosis expected at this age. Their strongly acid urine and high rates of excretion of hydrogen ion before administration of ammonium chloride should be noted. The dose of ammonium chloride in each subject was adequate to depress blood $\mathrm{tCO}_{2}$ well below threshold levels.

Three to 4 hours after completion of administration of ammonium chloride, blood $\mathrm{pH}$ and $\mathrm{tCO}_{2}$ were similar in both groups. No significant differences were observed in urinary $\mathrm{pH}$ or total excretion of hydrogen ion. Titratable acid in the infants was higher than in the children due to the greater rate of excretion of phosphate in the former group. Although the rate of excretion of ammonium was greater in the children, similar values were obtained when a comparison was made of excretion per $100 \mathrm{ml}$ creatinine clearance.

\section{Discussion}

Bicarbonate reabsorption. Tudvad, McNamara, and Barnett (13) performed tests of bicarbonate reabsorption and excretion in premature infants ranging in age from 8 to 37 days. The renal threshold for bicarbonate ranging from 22 to 24 mmoles per $\mathrm{L}$ in those infants is close to the range of 21.5 to 22.5 reported here in premature and full-term infants during the remainder of the first year of life. However, the maximal rate of reabsorption of bicarbonate of 2.5 to 2.6 mmoles per $100 \mathrm{ml} \mathrm{GF}$ during the first month of life is lower than the range of 2.6 to 2.9 mmoles per $100 \mathrm{ml}$ GF observed in the present study. The threshold observed in the young premature infant persists, apparently, throughout at least most of the first year of life, whereas the maximal rate of reabsorption appears to increase more rapidly than the threshold.

The maximal rate of reabsorption of 2.6 to 2.9 mmoles per $100 \mathrm{ml} \mathrm{GF}$ observed here in infants is virtually identical with the range of 2.6 to $3.0 \mathrm{ob}-$ served by Pitts and co-workers (6) in adults. However, subjects in the latter investigation received $\mathrm{NH}_{4} \mathrm{Cl}$ before study, had higher levels of $\mathrm{PCO}_{2}$ in blood during the study, and had their blood bicarbonate increased to much higher levels than in the study in infants. Although these differences limit precise comparison of the results of the two investigations, any effect of the different conditions in adults would be to increase the level of their $\mathrm{Tm}$. Therefore, it can be concluded that the Tm in infants is at least as high as in the mature subject.

It is of interest to relate these functional data to the observations of Fetterman, Shuplock, 
Philipp, and Gregg (14) on morphologic development of the kidney. Using microdissection techniques, these authors made measurements of glomerular surface area and proximal tubular volume of isolated nephrons from the kidneys of children varying in age at time of death from birth to 18 years. In comparison to the child of several years of age, the newborn infant demonstrated higher values for and a greater degree of heterogeneity in the ratio of glomerular surface area to proximal tubular volume. The heterogeneity demonstrated in the infant with regard to morphologic glomerulotubular balance suggests the possibility of corresponding functional heterogeneity. Nephrons with relatively low glomerular surface area, and, therefore, possibly low glomerular filtration rate (GFR) relative to tubular size, might be expected to saturate their reabsorptive capacity and to excrete filtered bicarbonate only when the plasma bicarbonate concentration reached high levels. More importantly, nephrons with a relatively large glomerular surface area (and GFR) might excrete bicarbonate at relatively low plasma levels, tending to lower the bicarbonate threshold.

Support of this formulation can be found in the construction presented in the insert of Figure 2, calculated according to the method of Smith (12), in which a frequency distribution curve of the ratio of glomerular filtration rate to maximal rate of bicarbonate reabsorption for groups of nephrons (r) is compared with the mean value for both kidneys (R). This method, applied previously only to examination of glucose reabsorption, provides a graphic presentation of the glomerulotubular balance of groups of nephrons compared to the mean value for glomerulotubular balance for both kidneys as a unit. The marked skewing to the right and the wide dispersion of $r / R$ values should be noted. It is perhaps of significance that this distribution of functional glomerulotubular balance is almost identical to the distribution of the ratio of glomerular surface area to proximal tubular volume found by Fetterman and associates in infants at term (14). However, their histogram of nephrons from the kidneys of infants $3 \frac{1}{2}$ to 5 months of age resembled the adult pattern, indicating that anatomical heterogeneity per se may explain only part of the functional heterogeneity which may persist throughout the first year of life.

As pointed out by Rieselbach and associates
(15) with regard to data obtained during glucose titration studies, splay in the titration curve of patients with renal disease may relate to alterations in the kinetics of the enzyme reactions underlying transport mechanisms, as well as to functional heterogeneity. Thus, an alternative explanation of the low threshold and marked splay observed in the infants is a possible difference in the kinetics of bicarbonate reabsorption during this period. However, it is difficult to explain the findings shown in the frequency distribution curve on this basis.

Other factors may modify the renal bicarbonate threshold and thus the concentration of bicarbonate in blood. In the studies of Tudvad and associates (13), adequate activity of carbonic anhydrase was suggested by the response observed to administration of a carbonic anhydrase inhibitor. Nothing in either that investigation or the present study suggested disturbances in extracellular volume or in potassium balance. The values for blood $\mathrm{PCO}_{2}$ in the infants reported here, however, as well as in other normal infants, are lower than those observed in older children or adults. Since a direct relationship has been demonstrated between blood $\mathrm{PCO}_{2}$ and bicarbonate reabsorption (16-18), the possible effects of hypocapnia on the bicarbonate threshold and the maximal rate of reabsorption must be considered. However, in contrast to subjects with respiratory alkalosis, in whom hypocapnia is primary and the renal reabsorption of bicarbonate is depressed secondarily, these infants show marked splay of their reabsorption curve with no apparent lowering of the Tm. Moreover, no correlation was present between blood $\mathrm{PCO}_{2}$ and threshold or maximal rate of reabsorption. It appears likely, therefore, that the hypocapnia observed in infants is a consequence and not a cause of their low blood bicarbonate concentration.

Excretion of acid. Previous studies have indicated major limitations in urinary acidification and excretion of hydrogen ion in infants during the first few days of life (19). It has been assumed generally that the same limitations apply to infants throughout the entire first year. However, very few data are available during this period (20-22). In the present study infants aged 1 to 16 months demonstrated no limitation in urinary acidification; mean urinary $\mathrm{pH}$ after administration of am- 
monium chloride was as low as in the older children.

All infants in the present study were fed cow's milk formulas, providing a high daily intake of phosphate with a high rate of urinary excretion. Therefore, it is not surprising that the rate of excretion of titratable acid was higher in the infants than in the older children (23).

The mean rate of excretion of ammonium in the infants was significantly less than in the children. When the relatively low glomerular filtration rates of the infants are taken into consideration, however, it appears likely that no qualitative difference is present in the renal mechanism for production of ammonia, but rather that the lower rate of excretion is related to renal size or tubular mass (19).

The rate of excretion of total hydrogen ion in the infants was not significantly different from that observed in the children, the higher rate of excretion of titratable acid in the younger age group balancing their lower rate of ammonium excretion.

Physiologic acidosis of the infant. The finding of lower values for blood $\mathrm{pH}$ and bicarbonate during the first year or two of life usually is attributed to an imbalance between the endogenous rate of production of metabolic hydrogen ion and the ability of the kidney to excrete that hydrogen ion (2). Although this type of imbalance does exist in subjects with renal insufficiency and those with distal renal tubular acidosis, it is associated with a positive balance of hydrogen ion (24), an unlikely circumstance to be found in a healthy growing subject. Furthermore, if the capacity to excrete hydrogen ion were the limiting factor, one would expect a difference in blood $\mathrm{pH}$ and total $\mathrm{CO}_{2}$ in infants fed high or low protein diets. Neither the data of Fomon, Harris, and Jensen (25) nor data from our own laboratory (26) have demonstrated such differences. Finally, the results of administration of ammonium chloride in the present study demonstrate that, at least beyond the first few weeks of life, the capacity of the infant to excrete hydrogen ion is similar to that of older children.

In subjects in hydrogen ion balance, the renal threshold for bicarbonate regulates its concentration in plasma, which normally remains at a level somewhat below the threshold, with almost total reabsorption of filtered bicarbonate (3). Increase of plasma bicarbonate above the threshold, due to acute ingestion or infusion of bicarbonate, is followed by incomplete reabsorption of filtered bicarbonate and renal excretion, with subsequent reduction of plasma and interstitial concentrations to levels below the threshold, at which point reabsorption of filtered bicarbonate is complete, excretion ceases, and a steady state is again reached. Conversely, reduction of plasma bicarbonate concentration below the threshold leads to complete reabsorption of filtered bicarbonate, net excretion of hydrogen ion by the kidney, leading toward restoration of the previous bicarbonate concentration in blood.

In their study of infants between the ages of 3 months and 2 years, Albert and Winters (2) found the $\mathrm{CO}_{2}$ content of arterialized capillary blood to be $21.1 \pm 1.9$ mmoles per $\mathrm{L}$ (mean $\pm \mathrm{SD}$ ). These data are in excellent agreement with the values that would be anticipated on the basis of the present observations on bicarbonate threshold.

After investigating bicarbonate reabsorption in infants, Tudvad and associates (13) concluded that "in healthy premature infants the maximal rate of reabsorption of bicarbonate is such that, in the absence of other factors, concentrations of bicarbonate in serum would be stabilized at values of 24 to $26 \mathrm{mEq}$ per L. Consequently, the physiologic acidosis of the premature infant cannot be explained on the basis of renal immaturity involving bicarbonate reabsorption." However, these authors did not consider that it is the level of the threshold and not the maximal rate of reabsorption of bicarbonate that determines its concentration in plasma. Therefore, even though reabsorptive capacity during the first year of life greatly exceeds the rate of reabsorption observed at the bicarbonate threshold, low threshold values result in low plasma concentrations.

\section{Acknowledgments}

We gratefully acknowledge the important contributions of the nursing staff of the Renal Unit, under supervision of Edna J. Francis, and the technical staff, under the direction of Amy B. Martinez.

\section{References}

1. Cassels, D. E., and M. Morse. Arterial blood gases and acid-base balance in normal children. J. clin. Invest. 1953, 32, 824. 
2. Albert, M. S., and R. W. Winters. Acid-base equilibrium of blood in normal infants. Pediatrics 1966, 37, 728.

3. Pitts, R F. Physiology of the Kidney and Body Fluids. Chicago, Year Book, 1963, p. 164.

4. Van Slyke, D. D., and J. M. Neill. The determination of gases in blood and other solutions by vacuum extraction and manometric measurement. J. biol. Chem. 1924, 61, 523.

5. Hastings, A. B., and J. Sendroy, Jr. The effect of variation in ionic strength on the apparent first and second dissociation constants of carbonic acid. J. biol. Chem. 1925, 65, 445 .

6. Pitts, R. F., J. L. Ayer, and W. A. Schiess. The renal regulation of acid-base balance in man. III. The reabsorption and excretion of bicarbonate. $\mathrm{J}$. clin. Invest. 1949, 28, 35.

7. Conway, E. J. Microdiffusion Analysis and Volumetric Error, 4th ed. New York, MacMillan, 1952.

8. Cotlove, E., H. V. Trantham, and R. L. Bowman. An instrument and method for automatic, rapid, accurate, and sensitive titration of chloride in biologic samples. J. Lab. clin. Med. 1959, 51, 461.

9. Schreiner, G. E. Determination of inulin by means of resorcinol. Proc. Soc. exp. Biol. (N. Y.) 1950, 74, 117.

10. Smith, H. W., N. Finkelstein, L. Aliminosa, B. Crawford, and $M$. Graber. The renal clearances of substituted hippuric acid derivatives and other aromatic acids in dog and man. J. clin. Invest. 1945, 23, 388.

11. Snedecor, G. W. Statistical Methods Applied to Experiments in Agriculture and Biology, 5th ed. Ames, Iowa. Iowa State University Press, 1956.

12. Smith, H. W. The application of saturation methods to the study of glomerular and tubular function in the human kidney in Lectures on the Kidney, Lawrence, University of Kansas, 1943, p. 85.

13. Tudvad, F., H. McNamara, and H. L. Barnett. Renal response of premature infants to administration of bicarbonate and potassium. Pediatrics 1954, 13, 4.

14. Fetterman, G. H., N. A. Shuplock, F. J. Philipp, and H. S. Gregg. The growth and maturation of human glomeruli and proximal convolutions from term to adulthood. Studies by microdissection. Pediatrics 1965, 35, 601.

15. Rieselbach, R. E., S. W. Shankel, E. Slatopolsky, H. Lubowitz, and N. S. Bricker. Glucose titration studies in patients with chronic progressive renal disease. J. clin. Invest. 1967, 46, 157.

16. Brazeau, P., and A. Gilman. Effects of plasma $\mathrm{CO}_{2}$ tension on renal tubular reabsorption of bicarbonate. Amer. J. Physiol. 1953, 175, 33.

17. Relman, A. S., B. Etsten, and W. B. Schwartz. The regulation of renal bicarbonate reabsorption by plasma carbon dioxide tension. $\mathrm{J}$. clin. Invest. 1953, 32, 972.

18. Schwartz, W. B., G. Lemieux, and A. Falbriard. Renal reabsorption of bicarbonate during acute respiratory alkalosis. J. clin. Invest. 1959, 38, 2197.

19. Hatemi, N., and R. A. McCance. Renal aspects of acid-base control in the newly born. III. Response to acidifying drugs. Acta paediat. (Uppsala) 1961, $50,603$.

20. Gordon, H. H., H. McNamara, and H. R. Benjamin. The response of young infants to ingestion of ammonium chloride. Pediatrics 1948, 2, 290.

21. Rubin, M. I., P. L. Calcagno, and B. L. Ruben. Renal excretion of hydrogen ions. A defense against acidosis in premature infants. J. Pediat. 1961, 59, 848.

22. Peonides, A., B. Levin, and W. F. Young. The renal excretion of hydrogen ion in infants and children. Arch. Dis. Childh. 1965, 40, 33.

23. Schiess, W. A., J. L. Ayer, W. D. Lotspeich, and R. F. Pitts. The renal regulation of acid-base balance in man. II. Factors affecting the excretion of titratable acid by the normal human subject. J. clin. Invest. 1948, 27, 57.

24. Goodman, A. D., J. Lemann, Jr., E. J. Lennon, and A. S. Relman. Production, excretion, and net balance of fixed acid in patients with renal acidosis. J. clin. Invest. 1965, 44, 495.

25. Fomon, S. J., D. M. Harris, and R. L. Jensen. Acidification of the urine by infants fed human milk and whole cow's milk. Pediatrics, 1959, 23, 113.

26. Edelmann, C. M., Jr. Unpublished observations. 